\title{
Preparation of mecA Biosensor Based On Gold Nanoparticles to Determine Methicillin Resistant Staphylococcus Aureus (MRSA) Strains from Human and Animals
}

\author{
H. Abd-El-Hady ${ }^{2}$, W. El-Said ${ }^{2}$, M. El-Enbaawy ${ }^{2}$,Taher A. Salah Eldin ${ }^{1, *}$ \\ ${ }^{I}$ Nanotechnology \& Advanced Material Central Lab, Agriculture Research Center, Giza, Egypt \\ ${ }^{2}$ Department of Microbiology, Faculty of Veterinary medicine, Cairo University, Giza, Egypt
}

\begin{abstract}
Nanobiosensors represents a recent sensitive accurate diagnostic tool than convenient diagnosis of microbial pathogen. Methicillin-resistant Staphylococcus aureus (MRSA) infection has increased steadily worldwide. In the present study a DNA nanobiosensor for mecA gene of MRSA detection was designed. Target gene detection was done by cross linking protocol (two probes method) using two different oligonucleotides probes that conjugated to two sets of gold nanoparticles (GNPs). The current method depended on optical properties of functionalized gold nanoparticles. Statistical analysis for the results showed specificity of $100 \%$ and sensitivity of $90.9 \%$ of the used technique in correlation with culture and standard coagulase tests as well as mecA PCR results. In conclusion: The presented mecA biosensor determined the correct genotype of MRSA strains in a colorimetric simple rapid procedure.
\end{abstract}

Key words: Nanobiosensor, Staphylococcus Aureus, Gold Nanoparticles, veterinary medicine, mecA gene

\section{Introduction}

Methicillin-resistant Staphylococcus Aureus (MRSA) is a critically important human pathogen that is also an emerging concern in veterinary medicine. It is present in a wide range of animal species, including dogs, cats, rabbits, horses, cattle, pigs, poultry, and exotic species, both as a cause of infection and in healthy carriers. Identification of MRSA in various species and in food has led to concerns about the roles of animals, both pets and livestock, in the epidemiology of MRSA infection and colonization in humans (Weese, 2010).Resistance to methicillin is mediated by the presence of penicillin-binding protein 2a, encoded by the mecA gene(Wielders et al., 2002).

To develop preventive measures, a rapid screening method, along with accurate and timely identification of MRSA, is essential. The existing techniques for doing so are either time-intensive (culturing of bacteria on selective media), relatively insensitive (use of latex agglutination), or expensive and easily susceptible to operator error (such as PCR)(Ramesh et al., 2004).

There are different approaches in diagnostics using gold nanoparticles (GNPs): (1) Utilization of the GNPs color change upon aggregation (Mirkin et al., 1996). (2) Use of GNPs as a core/seed that can be tailored nanoprobes for diagnosis (You et al., 2007). (3) Utilization of GNPs in electrochemical based metal deposition for signal enhancement (Castañeda et al., 2007). Single-stranded oligonucleotide targets could be detected using two different gold-nanoprobes such that each was functionalized with a DNA-oligonucleotide complementary to one half of the given target (Mirkin et al., 1996). The use of thiol-linked ssDNA-modified GNPs for the colorimetric detection of gene targets represents an inexpensive and easy to perform alternative to fluorescence or radioactivity based assays (Storhoff et al., 2004).

The method described in the present work was designed for clinical laboratories using oligonucleotides probe conjugated to gold nanoparticles. To avoid radioactivity, fluorescence, or target amplification (such as PCR), and use a simple and rapid hybridization-based approach for diagnosis of MRSA.

The procedures in present work involve five-step process

The first involves synthesis of GNPs in characters suitable for conjugation. The second step involves designation of a probe for mecA gene of MRSA in characters suitable for conjugation. The third step involves functionalization of GNPs with single stranded DNA probe specific for that gene. The forth step involves characterization and confirmation of conjugation process. The fifth step involves application of conjugated DNA-GNPs for diagnosis of mecA gene using cross linking method and determination of minimum detection limit of DNA target conc. 


\begin{abstract}
II. Materials and method:
1.1 Samples collection \& Preparation

A total of 215 samples were collected from three different species, (cattle, dogs and human) for isolation of MRSA during the period from January 2012 to August 2012.

Cattle samples were mastitic milk samples and septic wound from bovine's dairy farms while the dog's samples were septic wounds swabs and the human samples were collected from septic wounds and urinary tract infected patients at Ain-Shams hospital, Cairo, Egypt.

The collected samples were cultured onto Mannitol salt agar (Oxoid), Sheep blood agar and Baird-Parker agar (Oxoid) and incubated for $24-48$ hours at $37^{\circ} \mathrm{C}$. The suspected S. aureus colonies were characterized by culture, morphology and biochemically according to (Kateete et al., 2010).For determination of MRSA, the disk diffusion technique was adapted according to (Bailey et al., 1978) using Oxacillin and vancomycin antibacterial discs, DNA of MRSA was extracted using Qiagen Kits followed by PCR using primer pairs targeting mecA gene of MRSA. Primers and cycling conditions for extracted DNA determined in a manner as described by (Thomas et al., 2007). Primers were synthesized by Metabion Company, Germany. The PCR product was suspected to be $533 \mathrm{bp}$.
\end{abstract}

\title{
1.2 Preparation of $13 \mathrm{~nm}$ GNPs:
}

Prior to validation by GNPs-oligo probe assay, the colloidal GNPs were used. Synthesis of $13 \mathrm{~nm}$ Au-NP with citrate reduction method was done according to (Turkevich et al., 1951 and Ali et al., 2014). Sodium chloride, Sodium phosphate monobasic, sodium phosphate dibasic, Sodium citrate tribasic dihydrate (>99\%),gold(III) chloridetrihydrate and Dithiotheritol (DTT),all were of analytical grade and purchased from (Sigma). $(0.45 \mu \mathrm{m})$ acetate filter were from (Millipore).

All glasswares were cleaned with aqua regia, and then $50 \mathrm{ml}$ of $1 \mathrm{mM}$ hydrogen tetrochloroaurate (III) trihydrate was prepared with Nanopure water in volumetric flask $\left(0.01969 \mathrm{~g} \mathrm{Au}+50 \mathrm{ml} \mathrm{H}_{2} \mathrm{O}\right)$. While the gold solution was heated, $5 \mathrm{ml}$ of $38.8 \mathrm{mM}$ sodium citrate tribasic dihydrate was prepared with nanopure water in the volumetric flask $\left(0.05704 \mathrm{~g}\right.$ sodium citrate $\left.+5 \mathrm{ml} \mathrm{H}_{2} \mathrm{O}\right)$ then quickly all the sodium citrate solution was added and resealed. Reflux continued for $15 \mathrm{~min}$. The color of solution turned from yellow to black, to purple to deep red and stored at room temperature. High resolution Transmission Electron Microscope (HRTEM) (Tecnai, FEI Netherland) was used to image shape homogeneity, disparity and size of prepared GNPs by examination of particles individually. UV-Vis-NIR spectrophotometer (Varian, Cary 5000) was used to investigate characteristic absorption peak of gold nanoparticles. Dynamic light scattering (DLS) (Zeta sizer nano, Malvern, UK) was used to measure average homogenicity, dispersity and size of prepared gold nanoparticles. Zeta potential (Malvern,UK) was used to investigate surface negative charges deposited in gold nanoparticles.

\subsection{Probe design:}

Probe conserved sequence was designed for both genes mecA (Skov et al., 1999) with thiol linker to enable conjugation with colloidal GNPs and 10 polyT spacer. Thisthiol modified probes were purchased from Metabion-Germany and their sequences were as follow: Probe1: 5'- Thiol-(C6-S-S) (10 T)- TTT ATC GGA CGT TCA GTC ATT -3' Probe2: 5' - TCT ACT TCA CCA TTA TCG - (10 T) - (C6-S-S) Thiol - 3'

\subsection{Preparation of GNPs-oligo probe:}

Fresh solution of $1 \mathrm{ml}$ of $0.1 \mathrm{M}$ DTT molecular biology grade $\left(\mathrm{C}_{4} \mathrm{H}_{10} \mathrm{O}_{2} \mathrm{~S}_{2}\right.$, Serva) solution in the disulfide cleavage buffer was prepared, $100 \mu \mathrm{L}$ DTT solution was added to $5 \mathrm{nmol}$ of lyophilized thiolated DNA, wrapped in foil and left stand at room temperature for $2-3 \mathrm{~h} .15 \mathrm{~min}$ before the completion of disulfide cleavage, NAP-5 column (GE) was flushed with nanopure water. At least three column volumes of Nano pure water must flush through before adding DNA.100 $\mu \mathrm{L}$ of thiolated probe was added to the column after all the water ran through. Once the $100 \mu \mathrm{L}$ of thiolated probe were flowed into the column, $400 \mu \mathrm{L}$ of nanopure water was added to the column and allowed to flow through uncollected receptacles $600 \mu \mathrm{L}$ nanopure water then added to the column, and collected in $1.5 \mathrm{ml}$ microcentrifuge tubes. Collected DNA was fractionated to 2 fractions each was $300 \mu \mathrm{l}$ to ensure high concentration of yield.

The GNPs- oligo probe was synthesized using a previously described protocol (Hill and Mirkin, 2006). Briefly, the $5 \mathrm{nmol}$ thiol-modified oligonucleotide was initially incubated with $1 \mathrm{ml}$ of GNPs overnight in an orbital shaker at room temperature wrapped in aluminum foil. At the end of reaction, phosphate buffer (100 mM, pH7) was added to obtain a final concentration of $9 \mathrm{mM}$. The surfactant solution containing SDS was added, resulting in a concentration of $0.1 \%$ and incubated in an orbital shaker for 30 minutes. The salting solution $(2 \mathrm{M} \mathrm{NaCl}$ in $10 \mathrm{mM}$ PBS pH7) was divided into six doses and added to the above solution over the course of the two days to reach a final concentration of $0.3 \mathrm{M} \mathrm{NaCl}$. After the last salt addition the solution is allowed to equilibrate overnight at room temperature. Then centrifuged at $13000 \mathrm{~g}$ for 20 minutes and the precipitate was washed with $500 \mu \mathrm{L}$ of suspension buffer containing $10 \mathrm{mM}$ PBS (pH7.4), $150 \mathrm{mM} \mathrm{NaCl}, 0.1 \%$ SDS and re-suspended in 
$50 \mu \mathrm{L}$ of the same buffer. The fully functionalized GNPs-oligo probes retain the same color as the unmodified GNPs with no visible aggregates, and stored light-tight containers at room temperature until use. UVVis spectrophotometer, zeta sizer and Fourier transform infrared (FTIR) were used to characterize conjugated GNPs.

Hybridization assay and determination of detection limit of DNA target concentration (Bui et al., 2007)

$95 \mathrm{ml}$ from each DNA-functionalized GNPs (mecA) probes (probe $1+$ probe 2) solution was mixed and incubated at $37^{\circ} \mathrm{C}$ for 30 minutes . Target DNA was prepared in different concentration in $1,2.5,7.5$ and $10 \mu \mathrm{l}$ per $10 \mu \mathrm{l}$ of $10 \mathrm{mM}$ PBS. Different concentration of DNA were heated in water bath for $3 \mathrm{~min}$ at 95 ${ }^{\circ} \mathrm{C}$ then added to the mixture of probe. Whole mixture were placed at $65{ }^{\circ} \mathrm{C}$ for 5 minutes then left at room temp for 20 minute for hybridization process.

The negative control was non complementary DNA using mecA GNPs-oligo probe with $10 \mu 1$ of DNA of seven standard bacterial strains were obtained from American type culture collection $\{\mathrm{K}$. pneumoniae (ATCC 700603), P. vulgaris (ATCC13315), S. Typhi (ATCC 19430), S. Typhimurium (ATCC14028), E.aerogenes (ATCC13048) and S. aureus(ATCC 25923) and E. coli (ATCC 25922)\}. While, for positive control $10 \mu 1$ of DNA target of MRSA (ATCC 33591) was used.

Validation Assay Test (Skov et al., 1999)

It was applied for determination of specificity and sensitivity of technique under test (cross linking technique) in comparison with gold standard test (PCR). The following relations were applied;

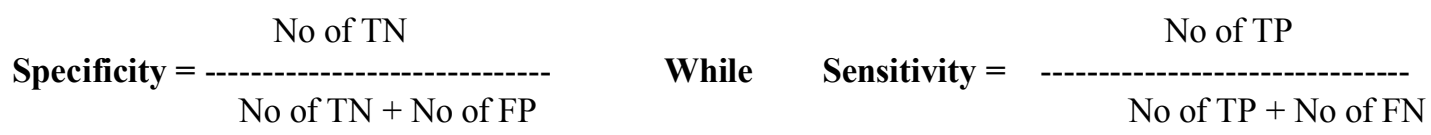

TN (True negative): Samples which were negative by PCR.

FP (False positives): Samples which were negative by PCR and positive with crosslinking technique.

TP (True positives): Samples which were positive by PCR.

FN (False negative): Samples which were positive by PCR and negative with cross linking tech.

\section{Results:}

By using bacteriological method, Oxacillin and vancomycin antibacterial testing, 44 isolates were identified as S. aureus and 10 as MRSA from 215 human, bovine and canine samples. The ten strains were positive for mecA gene and showing specific PCR products at 553 bp (Photo, 1).

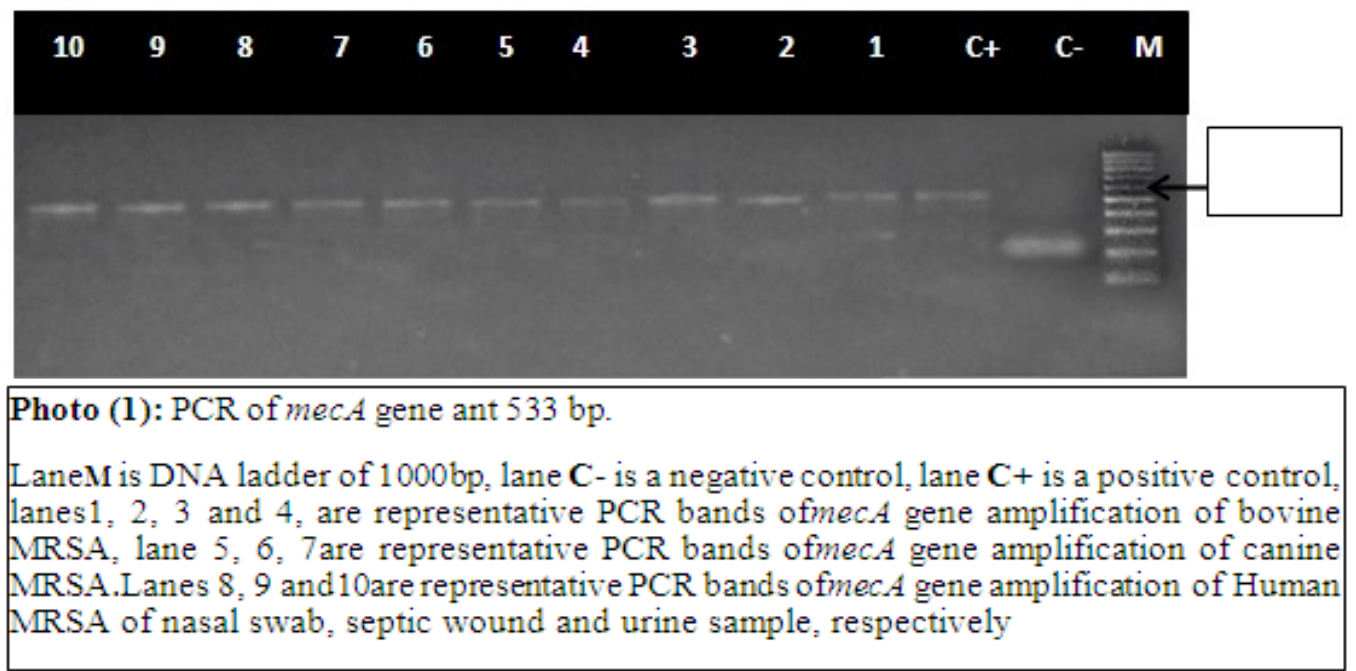

\section{Characterization of the prepared GNPs:}

Characterization of the prepared GNPs with High Resolution Transmission Electron Microscope (HRTEM) showed homogenous nanoparticles with mean diameter, 13 - $14 \mathrm{~nm}$ (Photo, 2). Zeta size measurement showed the average size of GNPs measured 13.45 (Photo,3). UV-Vis spectrophotometry of non-modified GNPs showed absorption peak of at $524 \mathrm{~nm}$ (Photo, 4). Negative net charge on GNPs (Citrate capping) was measured (Photo, 5) indicates surface charge to be $-26.6 \mathrm{mV}$. 


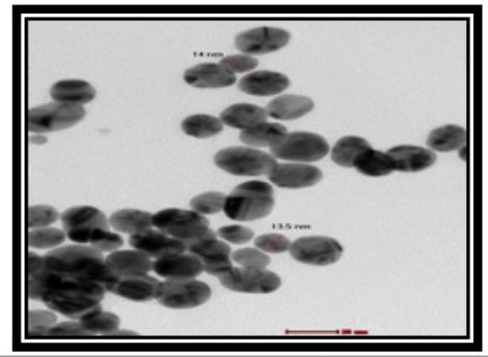

Photo (2): HRTEM micrograph showing gold nanoparticles (GNPS)

$$
\text { Withdiameter13-14 } \mathrm{nm}
$$

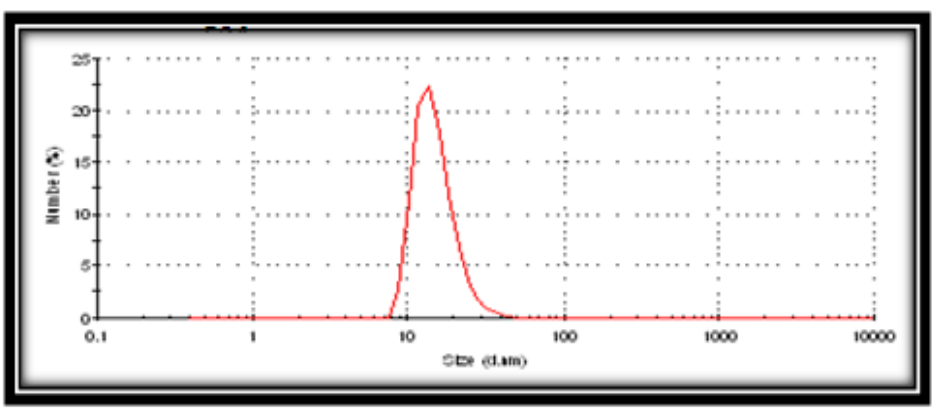

Figure (3): The size of GNPs (13.54 nm) by size measurement

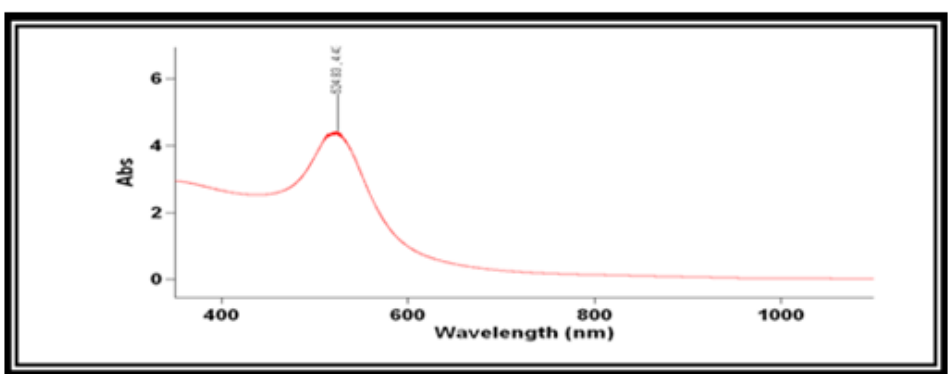

Figure (4): UV-Vis spectrophotometry of non-modified gold nanoparticles showing absorption peak of at $524 \mathrm{~nm}$.

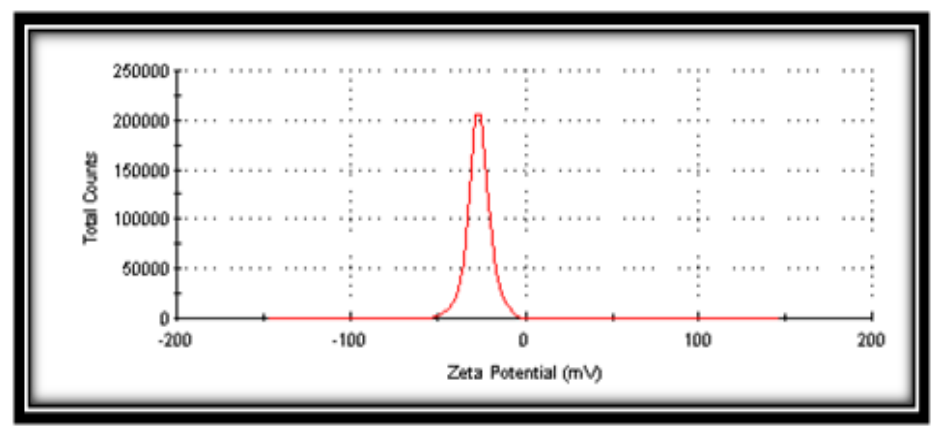

(5): Negative Net charge on gold nanoparticles (Citrate capping)

De-protection of thiolated probes (Reduction of thiolated probe by disulfide cleavage buffer) 
De-protection (Reduction) of protected thiolated probe with Dithiotheritol (DDT) resulted in a freshly reduced thiolated (SH) probe. Purification of freshly reduced thiolated probe resulted in purification of probes from DTT which is interfering with completion of conjugation process.

\section{Conjugation process}

Regarding to color of conjugated (Modified) gold nanoparticles, it was typically similar to non-modified one before conjugation, both were clear pinky in color with no visible aggregate (Photo.,6 and 7).
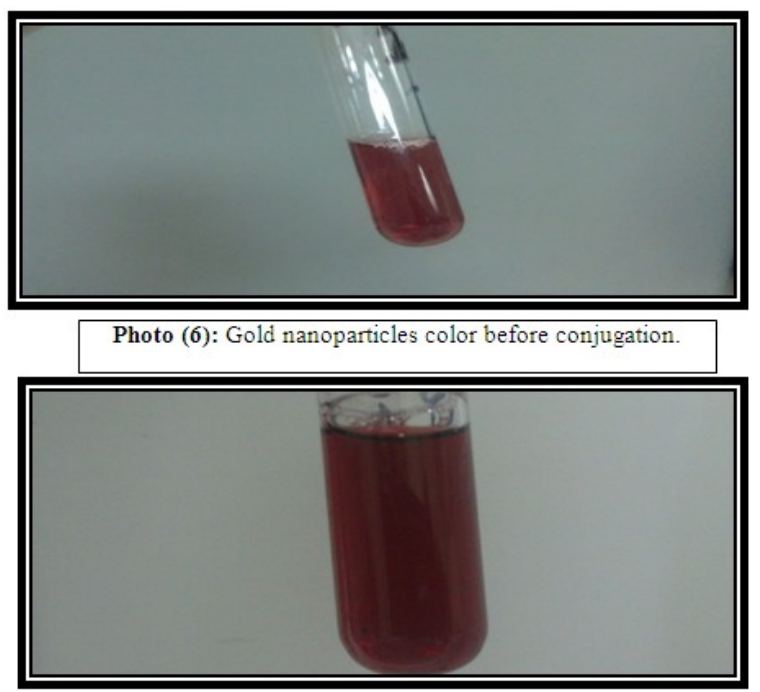

Photo (7): Gold nanoparticles color after conjugation.

\section{Characterization of gold sulfur bond formation}

After pelleting of modified GNPs through centrifugation at $13000 \mathrm{rpm}$ for $20 \mathrm{~min}$ and removal of supernatant to discard free non conjugated DNA, samples were re-suspended in assay buffer and tested with UV-Vis Spectroscopy: Spectrophotometer showed 2 peaks of absorption, one corresponding to GNPs at $520 \mathrm{~nm}$ and the other was for conjugated DNA at $260 \mathrm{~nm}$ (Photo, 8)

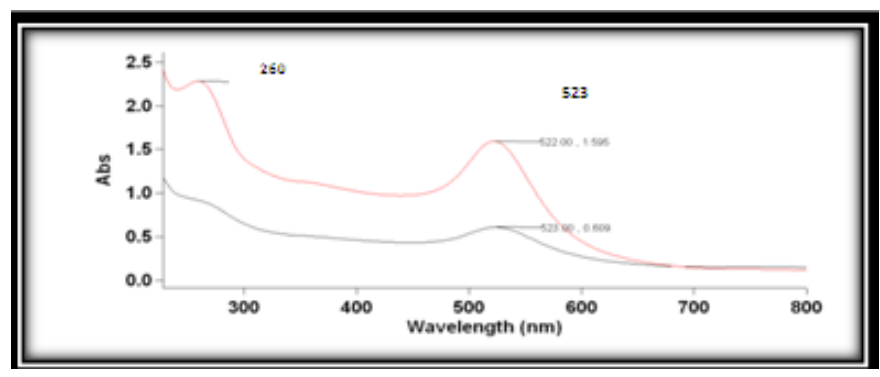

Photo, 8: UV-Vis Spectroscopy: Spectrophotometer showed 2 peaks of absorption, one corresponding to GNPs at $520 \mathrm{~nm}$ and the other was for conjugated DNA at $260 \mathrm{~nm}$

\section{Fourier transform infrared spectroscope (FTIR)}

FTIR showed absence of SH bonds which indicated breakage of it to form gold-sulfur bond with GNPs. It can also be found that there are two bands at 2922 and $2857 \mathrm{~cm}^{-1}$ as shown in Photo (9) in which were attributed to the symmetric and anti-symmetric stretching vibrations of $-\mathrm{CH}_{2}$, respectively. The sample showed no detectable characteristic bands of S-H vibration in the range of $2500-2600 \mathrm{~cm}^{-1}$, which suggested that the S-H bond was broken upon binding to the gold particle surface to form the bond of S-Au. Also, particles size measurements determined slight increase in GNPs size due to conjugation process. Where the size was increased from 13.45 $\mathrm{nm}$ (unconjugated) to $21.4 \mathrm{~nm}$ (conjugated) as shown in Photo (10). 


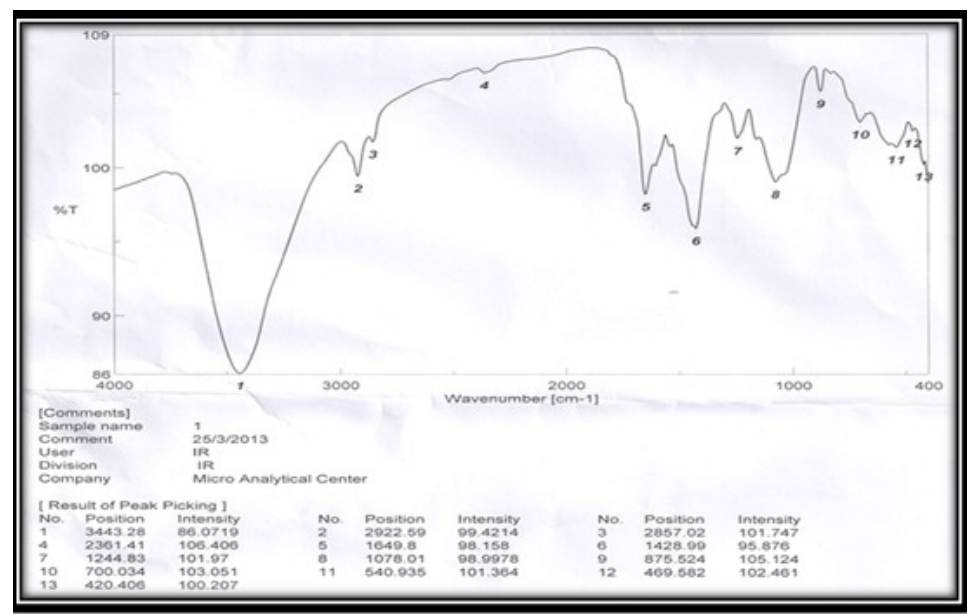

Figure (9): FTIR of mecA probe conjugated to 13 nm gold nanoparticles, showing absence of peak specific for thiolgroup at $2500-2600$.

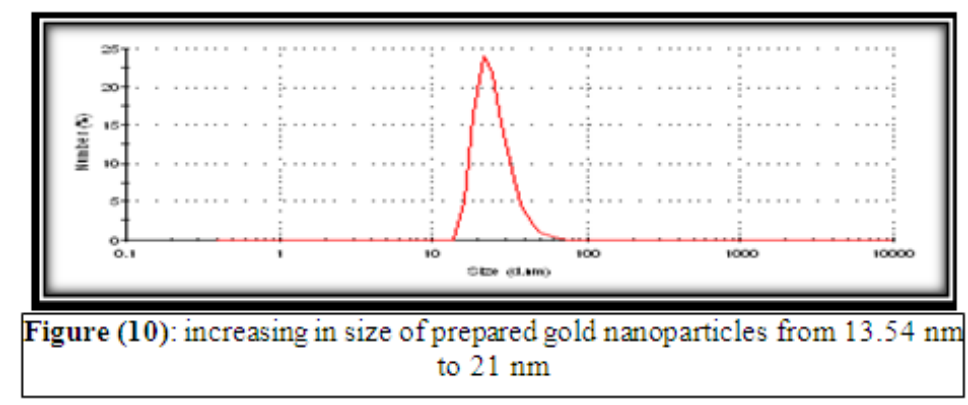

Application of cross linking techniques on mecA probe for detection of mecA gene of MRSA.

After application of the technique and placing of tubes in the room temperature, Positive result showed red shifting by change of color of modified GNPs from pinky to purple with absorption peak about $700 \mathrm{~nm}$ (Fig. 11) that can be observed visually .Negative result due to DNA concentration below minimum detection limit and control negative showed no change of color and remained pinky with absorption peak of $524 \mathrm{~nm}$ (Fig., 12).

Results were variable according to DNA concentration as the following.

Six from 10 strains were positive with DNA amount of $7.5 \mu 1$ and 9 from 10 strains were positive with amount of $10 \mu \mathrm{l}$ (Photo13). While all strains were negative with target DNA amount of $1 \mu 1$ and $2.5 \mu \mathrm{l}$ (Photo 14). So the minimum detection limit of this cross linking method was about $100 \mathrm{ng}$ of target DNA.
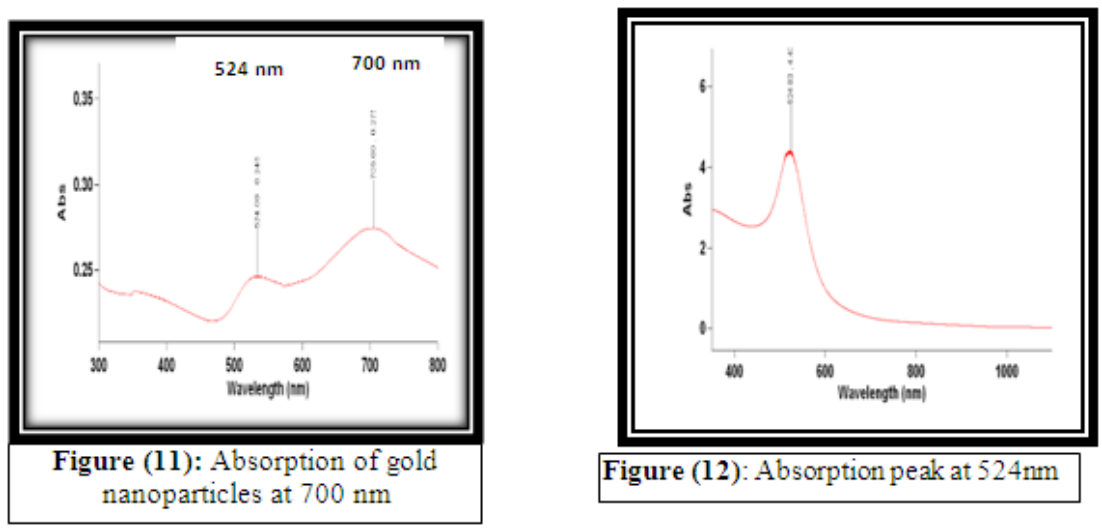

Figure (12): Absorption peak at $524 \mathrm{~nm}$ 

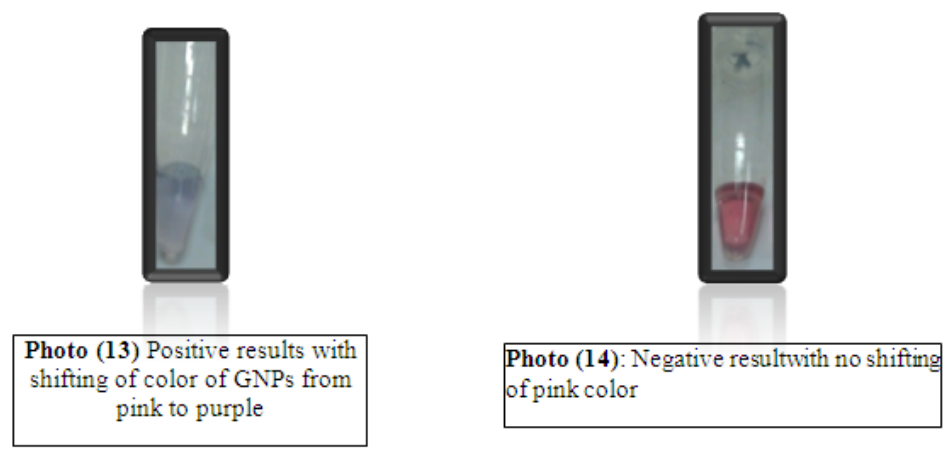

Cross-linking Hybridization assay application of mecA probe on bacterial spp. other than MRSA was negative (no change of color and remained pinky with absorption peak of $520 \mathrm{~nm}$ ).

Determination of specificity and sensitivity assay for cross linking technique.

The specificity of the cross liking with the concentration of $1,2,7.5$ and $10 \mu 1$ was $100 \%$. While the sensitivity was $50,50,71.14$ and $90.9 \%$, respectively.

\section{Discussion}

Staphylococcus aureus is one of the most important human pathogens, causing both nosocomial and community-acquired infections (Myles and Datta, 2012). In the present study, 44 samples of S. aureusstrains were isolated by bacteriological methods. MRSA strains were detected by Oxacillin and vancomycin antibacterial testing and PCR from bovine (4), canine (3), and human (3). These MRSA were isolated from nasal swab, septic wound and urine samples of contact animals (bovine, canine) and human, respectively. To develop preventive measures, a rapid screening method of MRSA, along with accurate and timely identification, with reliable specificity, high sensitivity, and low cost is essential, to be viable option for widespread clinical use.

There is an intense effort devoted toward development of new labeling and detection methodologies that enable sensitive and low-cost detection of nucleic acids for gene expression analysis and single nucleotide polymorphisms identification (Storhoff et al., 2004).

In the present study, nanotechnology was applied and positioned for diagnosis of microbial pathogen through designing of DNA biosensor. More clearly, sensing element of sensors was a conserved sequence of probes to detect mecA gene sequence of MRSA while, signal transducer was $\approx 13 \mathrm{~nm}$ spherical GNPs and produces a colorimetric signal in response to the analyte detection, which was DNA target aforementioned gene.

The effect of size and curvature of prepared AuNP where nanoparticles synthesized in round $13 \mathrm{~nm}$, to ensure high curvature and high DNA loading density according to (Hurst et al., 2006) who explored the relationship between nanoparticle size and DNA loading.

The surface of GNPs can be tailored by ligand functionalization to selectively bind biomarkers. Thiol-linking of DNA and chemical functionalization of GNPs are the most common approaches (Baptista et al., 2008). In this study, colloidal gold was synthesized with citrate reduction method following (Turkevich et al., 1951). Citrate capped nanoparticles are very stable in addition, the citrate capping can be replaced easily and the gold surface can be functionalized with various ligand such as DNA and peptides (Huang et al., 2007). In this study probes for mecA gene were designed with thiol cross linker. Each set of conjugated GNPs was complementary to one end of the mecA gene and two probe aligned in tail to tail fashion onto the target.

The length of probes used was from 20 and 21 for probe 1 of mecA and probe 2 mecA, respectively. The selected length ensured optimum immobilization according to (Singh et al., 2010). In the current study different spacers were used. For thiolated probe designed for mecA, polyT were used not poly A, as DNA strands containing the A10 spacer were more likely to lie on the Au nanoparticle surface compared to DNA containing the T10 spacer leading to further reducing DNA loading (Hurst et al., 2006).

Different concentrations from MRSA target DNA were used. Concentrations which were used were gradually increasing starting from original DNA concentration in $(\mathrm{ng} / \mu \mathrm{l})$. Amounts of target DNA were 1, 2.5, 7.5 and $10 \mu l$ per total volume which was $200 \mu$. Positive results were agree with (Bui et al., 2007) as the positive results were showed as shifting of color of conjugated GNPs from pink to purples in which indicated aggregation of particles and formation of polymeric network causing decreasing of inter-particles distance. Such physical explanation was done by (Elghanian, 1997)and (Radwan and Azzazy, 2009) who also mentioned that hybridization of the GNPs-labeled probe to the target caused aggregation and a change of the solution form pinky red to purple blue. 
Minimum detection limit was $\sim 100 \mathrm{ng}$ target DNA and the best volume to be used in hybridization assay was $10 \mu \mathrm{l}$ from target DNA per $200 \mu \mathrm{l}$ total reaction volume.

Results of hybridization assay with conjugated GNPs were compatible with conventional gold standard method of culturing, biochemical and PCR.

For determination of specificity of cross linking protocol and measurement of test validation, the same procedure was applied on bacterial DNA target of other than methicillin resistant Staphylococcus aureus. The amount of DNA target was $10 \mu \mathrm{l}$ to neglect minimum detection limit effect and positive control tube.

Statistical analysis of such protocol gave highest sensitivity of $90.9 \%$ at $10 \mu \mathrm{l}$ of DNA target per $200 \mu \mathrm{l}$ total reaction volume and specificity of $100 \%$ for detection of mecA gene.

\section{In conclusion}

The mecA nanobiosensor (gold-based nanoparticles) determined the correct genotype of MRSA strains in a colorimetric simple few hour's procedure. This technique can be used to screen the present of MRSA, after growth in selective medium, and found excellent correlation with culture and standard coagulase tests as well as mecA PCR results with high sensitivity and specificity.

\section{Acknowledgment}

The author thanks the research group at Nanotechnology \& Advanced Materials Central Lab (NAMCL), Agriculture Research Center, Giza, Egypt, for their valuable support and contribution in designing, synthesis and characterization of the GNPs and the mecA nanobiosensor.

\section{Reference}

[1]. Ali, M.A., Eldin, T.A.S., Moghazy, G.M. El, Tork, I.M., Omara, I.I., 2014. Detection of E . coli O157 : H7 in feed samples using gold nanoparticles sensor. Int.J.Curr.Microbiol.App.Sci 3, 697-708.

[2]. Bailey, W.R., Finegold, S.M., Martin, W.J., Scott, E.G., 1978. Bailey and Scott's Diagnostic microbiology: a textbook for the isolation and identification of pathogenic microorganisms. C. V. Mosby.

[3]. Baptista, P., Pereira, E., Eaton, P., Doria, G., Miranda, A., Gomes, I., Quaresma, P., Franco, R., 2008. Gold nanoparticles for the development of clinical diagnosis methods. Anal. Bioanal. Chem. 391, 943-50. doi:10.1007/s00216-007-1768-Z

[4]. Bui, M.-P.N., Baek, T.J., Seong, G.H., 2007. Gold nanoparticle aggregation-based highly sensitive DNA detection using atomic force microscopy. Anal. Bioanal. Chem. 388, 1185-90. doi:10.1007/s00216-007-1354-4

[5]. Castañeda, M.T., Alegret, S., Merkoçi, a., 2007. Electrochemical Sensing of DNA Using Gold Nanoparticles. Electroanalysis 19, $743-753$. doi:10.1002/elan.200603784

[6]. Elghanian, R., 1997. Selective Colorimetric Detection of Polynucleotides Based on the Distance-Dependent Optical Properties of Gold Nanoparticles. Science (80-. ). 277, 1078-1081. doi:10.1126/science.277.5329.1078

[7]. Hill, H.D., Mirkin, C.A., 2006. The bio-barcode assay for the detection of protein and nucleic acid targets using DTT-induced ligand exchange. Nat. Protoc. doi:10.1038/nprot.2006.51

[8]. Huang, X., Jain, P.K., El-Sayed, I.H., El-Sayed, M.A., 2007. Gold nanoparticles: interesting optical properties and recent applications in cancer diagnostics and therapy. Nanomedicine 2, 681-693. doi:10.2217/17435889.2.5.681

[9]. Hurst, S.J., R., L.-J.A.K., Mirkin, C.A., 2006. Maximizing DNA Loading on a Range of Gold Nanoparticle Sizes. Anal Chem. 78, 83138318. doi:10.1021/ac0613582.Maximizing

[10]. Kateete, D.P., Kimani, C.N., Katabazi, F. a, Okeng, A., Okee, M.S., Nanteza, A., Joloba, M.L., Najjuka, F.C., 2010. Identification of Staphylococcus aureus: DNase and Mannitol salt agar improve the efficiency of the tube coagulase test. Ann. Clin. Microbiol. Antimicrob. 9 , 1-7. doi:10.1186/1476-0711-9-23

[11]. Mirkin, chad A., Letsinger, R.L., Mucic, R.C., Storhoff, james J., 1996. A DNA-based method for rationally assembling nanoparticles into macroscopic materials. Nature 382, 607-609.

[12]. Myles, I. a, Datta, S.K., 2012. Staphylococcus aureus: an introduction. Semin immunopathol 34, 181-184. doi:10.1007/s00281-011-0301-9

[13]. Radwan, S.H., Azzazy, H.M.E., 2009. Gold nanoparticles for molecular diagnostics. Expert Rev. Mol. Diagn. 9, 511-24. doi:10.1586/erm.09.33

[14]. Ramesh, R., Buckingham, W., Domanus, M., Gieser, L., Klein, K., Gregory, K., Prokhorova, A., V., R.P., 2004. Sensitive Assay for Identification of Mrthicillin-Resisitant Staphylococcus aureus, Based on Direct Detection of Genomic DNA by use of Gold Nanoparticles Probes. Clin. Chem. 50, 1930-1952.

[15]. Singh, A., Snyder, S., Lee, L., Johnston, A.P.R., Caruso, F., Yingling, Y.G., 2010. Effect of Oligonucleotide Length on the Assembly of DNA Materials: Molecular Dynamics Simulations of Layer-by-Layer DNA Films. Langmuir 26, 17339-17347. doi:10.1021/la102762t

[16]. Skov, R.L., Pallesen, L. V, Poulsen, R.L., Espersen, F., 1999. Evaluation of a new 3-h hybridization method for detecting the mecA gene in Staphylococcus aureus and comparison with existing genotypic and phenotypic susceptibilty testing methods. Antimicrob. Chemother. 43, $467-475$.

[17]. Storhoff, J.J., Lucas, A.D., Garimella, V., Bao, Y.P., Müller, U.R., 2004. Homogeneous detection of unamplified genomic DNA sequences based on colorimetric scatter of gold nanoparticle probes. Nat. Biotechnol. 22, 883-887.

[18]. Thomas, L.C., Gidding, H.F., Ginn, a N., Olma, T., Iredell, J., 2007. Development of a real-time Staphylococcus aureus and MRSA (SAM-) PCR for routine blood culture. J. Microbiol. Methods 68, 296-302. doi:10.1016/j.mimet.2006.09.003

[19]. Turkevich, J., Stevenson, P.C., Hillier, J., 1951. A study of the nucleation and growth processes in the synthesis of colloidal gold. Discuss. Faraday Soc. 11, 55-75. doi:10.1039/DF9511100055

[20]. Weese, J.S., 2010. Staphylococcus aureus 51, 233-244.

[21]. Wielders, C.L.C., Fluit, A.C., Brisse, S., Verhoef, J., Schmitz, F.J., 2002. mecA Gene Is Widely Disseminated in Staphylococcus aureus Population. Clin. Microbiol. 40, 3970-3975. doi:10.1128/JCM.40.11.3970

[22]. You, C.-C., Miranda, O.R., Gider, B., Ghosh, P.S., Kim, I.-B., Erdogan, B., Krovi, S.A., Bunz, U.H.F., Rotello, V.M., 2007. Detection and identification of proteins using nanoparticle-fluorescent polymer "chemical nose" sensors. Nat. Nanotechnol. doi:10.1038/nnano.2007.99 